\title{
EVALUATION OF FINITE ELEMENT ANALYSIS AS A TOOL TO PREDICT SEA LOADS WITH THE AID OF TRIALS DATA.
}

W. Amin, School of Engineering, University of Tasmania, Hobart, Australia, M. Davis, School of Engineering, University of Tasmania, Hobart, Australia, and G. Thomas, Australian Maritime College, University of Tasmania, Launceston, Australia

\section{SUMMARY}

The current study evaluates the using of finite element modelling as a tool to predict sea loads for high-speed wave piercing catamarans based on sea trials data. The current sea trials data is for HSV-2 Swift; a 98 meter Incat Seaframe designed by Revolution Design and configured to U.S. Navy specification. The ship was instrumented with a system of sensors and data acquisition system to monitor structural response, ship motions, performance, and sea conditions. A detailed finite element model of a similar vessel was modified to represent the existing ship configuration. A new methodology is presented to investigate sea loads during trials, and the results from the FE analysis are compared to trials data. It was found that a direct comparison of strain time histories of trial and finite element analysis, was hard to achieve. However, the FE RMS strains are in good agreement with trials RMS strains and approached a correlation coefficient of $95.5 \%$ for perfect heads seas condition and $80.2 \%$ for head seas with a slight loading asymmetry.

\section{NOMENCLATURE}

$C F_{x} \quad$ Calibration factor at position $x$.

$M_{x} \quad$ Applied bending moment at position

$\varepsilon_{x} \quad$ Strain at position $x$ (micro strain).

$Z_{x} \quad$ Section modulus at position $x\left(\mathrm{~m}^{3}\right)$.

$E \quad$ Modulus of elasticity $\left(\mathrm{N} \mathrm{m}^{-2}\right)$.

$s(t) \quad$ Unit step function.

$\varepsilon_{d} \quad$ Strain difference between port and

$\sigma_{d} \quad$ Standard deviation of $\varepsilon_{d}$ (micro

MPC Multi-point constraint elements

$M$

$A_{33}$

$A_{35}$

$a_{33}$

$B_{33}$

$b_{33}$

$B_{35}$

$C_{33}$

$C_{35}$ pitch $\left(\mathrm{kg} \mathrm{m} \mathrm{rad}^{-1}\right)$.

$\bar{\xi}_{3}$
$\bar{\xi}_{3}$
$\bar{\xi}_{3}$
$\bar{\xi}_{5}$
$x(\mathrm{~N} \mathrm{~m})$. starboard gauges (micro strain). strain).

Ship's mass (kg).

Added mass in heave $(\mathrm{kg})$.

Added mass in coupled heave and

Sectional added mass in heave

$\left(\mathrm{kg} \mathrm{m}^{-1}\right)$

Damping in heave $\left(\mathrm{kg} \mathrm{s}^{-1}\right)$.

Sectional damping in heave $\left(\mathrm{Kg} \mathrm{m}^{-1} \mathrm{~s}^{-1}\right)$

Damping in coupled heave and pitch $\left(\mathrm{N} \mathrm{s} \mathrm{rad}^{-1}\right)$.

Restoration coefficient in heave $\left(\mathrm{N} \mathrm{m}^{-1}\right)$.

$\bar{\xi}_{5}$

Restoring coefficient in coupled heave and pitch $\left(\mathrm{N} \mathrm{rad}^{-1}\right)$.

LCG vertical displacement (m).

LCG vertical velocity $\left(\mathrm{m} \mathrm{s}^{-1}\right)$.

LCG vertical acceleration $\left(\mathrm{m} \mathrm{s}^{-2}\right)$.

Pitch angular displacement (rad). $\omega$

$C_{L}$

$\alpha$

$\delta$

$A_{f}$

$\rho$

$U$

$V_{r}$

$\varsigma(t)$

$T_{H}$

$\xi_{c i}$

$\xi_{s i}$



(n)

.

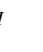

${ }^{D}$

${ }_{3}^{K}$

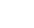

.

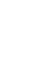

L

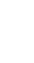

P

r

r

$(t)$

$\xi_{s i}$

$V_{r i}$

$\omega_{e i}$

$A_{n i}$

$B_{n i}$

$T$

$x$

cc
Pitch angular velocity $\left(\operatorname{rad~s}^{-1}\right)$.

Pitch angular acceleration ( $\mathrm{rad} \mathrm{s}^{-2}$ ).

Vertical hydrostatic forces $(\mathrm{N})$.

Vertical diffraction forces $(\mathrm{N})$.

Vertical Froude-Krylov forces representing only the dynamic components $(\mathrm{N})$.

T-foil lift forces (N).

Gravity acceleration $\left(\mathrm{m} \mathrm{s}^{-2}\right)$.

Time (s).

Wave frequency (rad.).

T-foil lift coefficient.

T-foil angle of attack (deg.).

T-foil flap angle (deg.).

T-foil projected area $\left(\mathrm{m}^{2}\right)$.

Sea water density $\left(\mathrm{Kg} \mathrm{m}^{-3}\right)$.

Ship speed $\left(\mathrm{m} \mathrm{s}^{-1}\right)$.

Wave relative velocity w.r.t. ship $\left(\mathrm{m} \mathrm{s}^{-1}\right)$

Wave height record (m)

Wave height record's length (s)

$i^{\text {th }}$ cosine component of the decomposed waterline $(\mathrm{m})$.

$\mathrm{i}^{\text {th }}$ sine component of the decomposed waterline $(\mathrm{m})$.

$\mathrm{i}^{\text {th }}$ wave relative velocity w.r.t. ship.

$\mathrm{i}^{\text {th }}$ encounter frequency.

Fourier transform cosine coefficient.

Fourier transform sine coefficient.

Instantaneous time (s).

Longitudinal position measured from transom (m).

Correlation coefficient. 


$\begin{array}{ll}\varepsilon_{F} & \text { Numerical strain }\left(\mu_{\text {strain }) .}\right. \\ \varepsilon_{T} & \text { Trial's strain ( } \mu_{\text {strain }) .} \\ \bar{\varepsilon}_{F} & \text { Average numerical strain. } \\ \bar{\varepsilon}_{T} & \text { Average trial's strain. } \\ \sigma_{F} & \text { Numerical strain standard deviation. } \\ \sigma_{T} & \text { Trial's strain standard deviation. } \\ n & \text { Sample size. }\end{array}$

\section{INTRODUCTION}

The use of finite element modelling as a tool to predict sea loads for high-speed wave-piercing catamarans based on sea trials data is evaluated in this paper. Finite element analysis has been used extensively in the structural design of high-speed ships to predict the ship's structural performance during its lifetime according to, in most cases, a set of predefined loads by classification societies. It has also been used to predict the natural frequencies of a ship's structure for both dry and wet modes, Tanaka et al. [1], investigated the torsional strength of a container ship by means of finite element analysis and full-scale tests. The only load considered was cargo loading, which was arranged port and starboard so that a known torsional load was applied; the buoyancy load was neglected. Full-scale measurements were conducted in still water conditions and compared favourably with the FE analysis. The deflections of Great Lakes ore carriers in the way of the propulsion machinery were investigated by Kaldjian et al. [2]. The loads considered in the finite element analysis were the hydrostatic loading, cargo loads, propulsion thrust and torque. Pegg et al. [3] studied the bow flare plate stresses under dynamic wave loading. The ship's bow was instrumented with 10 pressure transducers and a finite element model of the ship's bow was constructed and loaded according to the measured loads. Hay and Bourne [4] used a coarse mesh finite element model of a naval combatant to extract calibration factors between applied known loads (vertical bending moment) and the resulting stresses at the strain gauges locations during sea trials. These calibration factors were then used to determine the actual sea loads. The same procedure was used by Sikora et al. [5], Sikora et al. [6] and Stredulinsky et al. [7]. Yamamoto et al. [8] investigated the global strength of wave piercing catamarans based on several 'quasi-dynamic' loadings as defined in the classification rules. As the superstructure was rigidly connected to the hull girder, unlike the INCAT versions that utilise resilient mounts, it was concluded that omitting the superstructure is very conservative in global strength analysis. No comparison with trial tests was carried out. Yakimoff [9] ran a normal mode solution on the full global model of Incat Tasmania's 81 $\mathrm{m}$ wave piercer. The model was altered to simulate the delivery condition weight distribution. Additional mass was designated to each hull to nominally represent the mobilised boundary layer of water adjacent to the submerged portions of the vessel. A significant global bending mode was revealed at a frequency of about $2.95 \mathrm{~Hz}$. The concept design of the BC Ferries' catamarans was introduced by Tulk [10]. Load cases according to DNV rules, were used in the global structural analysis as well as fatigue analysis. A detailed model for the waterjet room and transom flange was also made. However no comparison with trial data was made.

The type of analysis where hydrostatic and inertia force systems are only considered is usually referred to as 'quasi-static'analysis. However, there is no distinct definition for the term 'quasi-static analysis'. Phelps [11] defined it as the balancing of the ship on an imaginary design wave so that the summation of all forces and moments (ideally) equals to zero. Ship motions are not introduced to the balancing equations, i.e., no acceleration. Cabos et al. [12] presented the package GL.ShipLoad capabilities in calculating static and hydrodynamic pressures due to waves and combining both types of loads in a quasi-static load case which implies that hydrodynamic terms are considered in such an analysis. Hermundstad [13] related the quasi-static nature of a load case to the frequency of structural response. Low wave encounter frequencies, in the range of 2.5-3.5 Hz, represent long waves that are comparable to the ship's length.

Planing craft were studied by Rosen [14] and resulted in the definition that a quasi-static response is where the response frequencies are lower than the eigenfrequencies of the structure. Wave slamming loads on a ship-shaped FPSO's bow was investigated by Wang et al. [15]. A criterion, considering the plate's natural period, was set to decide whether to solve the problem as a quasi-static or dynamic problem. If the impulse duration was longer than the natural period of the impacted plate, the response of the plate was expected to be static. The load model was calculated according to the applied pressures. Classification society rules such as D.N.V. [16] has specified a design load case that takes into account the ship motions (vertical acceleration) in calculating the maximum longitudinal bending moment the ship would be subjected to. The procedure is to balance the ship statically on a sine wave of a certain height, length and phase angle so that the maximum resulting bending moment is not less than that specified by the rules. Although the method of calculation seems to be static, the motion accelerations were included indirectly. The inertia forces are superimposed on weight forces and then balanced against hydrostatic loading under the sine wave. Thomas [17] used the same procedure in a study on large high speed wave piercing catamarans to estimate the impact force due to an extreme slamming event.

Finite element analysis has previously been used to reverse engineer the structural ship design problem through using the full scale structural response to predict the applied loads, Hay and Bourne [4], Sikora et al. [5], Stredulinsky et al. [7], and Sikora et al. [6]. This was usually done by generating strain gauges 
calibration factors through application of a known wave load to the finite element model. The calibration factors can be defined as the ratio between the known applied load at the strain gauge location and the corresponding deformation expressed in strain values. These calibration factors are then used to convert the actual strains at the strain gauge locations into loads, namely bending moments, according to:

$C F_{x}=\frac{M_{x}}{\varepsilon_{x}}=E Z_{x}$

Equation (1) states that the calibration factor is load independent and hence it can be used to derive the bending moment distribution whatever the loading condition is. However, the loading distribution remains questionable. Two loading distributions of intensity $q$ and $3 q$ over a simply supported beam are used to highlight the methodology drawback towards the prediction of load distributions, Figure 1. The mid-span bending moment is the same for both cases, $q L^{2} / 12$, which indicates that single point strain measurement, located mid-span is completely misleading and does not predict the corresponding load distribution. With three measuring points, a more accurate bending moment distribution can be obtained. However, the corresponding loading condition can not be known with certainty beyond the measuring positions; i.e. from the beam edge to the first strain gauge position. Similarly, if the strain gauges are located in the same manner in a ship, the load distribution over the forward bow area, which is subjected to local load effects such as slamming and shipping of green seas, would not be known. Moreover, it would be extremely challenging to predict the load distribution over the middle part of the ship if the strain gauges were located there. This is due to the fact that the load distribution depends on the fitting of the three bending moment values whether it is second or third degree fitting or even higher.

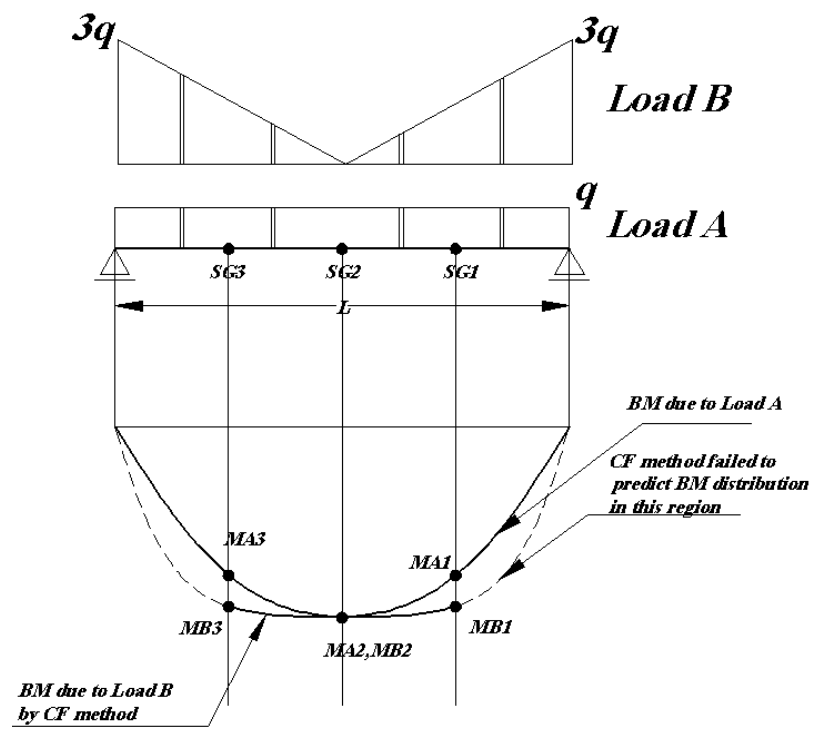

Figure 1, Strain gauge calibration factor limitations

\section{SCOPE OF WORK}

The reason for using the finite element method in this study is to develop a load distribution so that the strains derived by the finite element analysis match those obtained through trials. The applied load distribution in the finite element model will be derived based on sea trials data, namely the time records of wave height, relative bow motion, centre of gravity vertical acceleration, bow vertical acceleration, roll angle, pitch angle and T-foil data. Sea trials data will be used to define the actual water profile during a certain instant as well as the ship position relative to the water surface. Regular samples; i.e. no slamming or whipping, in head seas will be selected. Hydrostatic forces expressed as the hydrostatic pressure will only be included while the dynamic pressure components will be excluded. The hydrodynamic coefficient of the added mass and damping will be investigated in terms of their effect on the results accuracy. If successful this study will form the preliminary stage in slamming load analysis, where systematically changed slam loads (including location, distribution and intensity) over the centre bow area will be applied in the finite element model until the best match with trial's strains is obtained.

\section{SEA TRIALS DATA ANALYSIS}

The current sea trials data is for a 98 meter Incat Seaframe designed by Revolution Design and configured to U.S. Navy specification. The longitudinal vertical bending response was monitored by six strain gauges sampling at $100 \mathrm{~Hz}$ located on the keel centre girder at three longitudinal locations port and starboard. A wave radar was installed in the bow area to monitor the wave height and bow vertical acceleration at the same sampling rate. Trials of HSV-2 were conducted by Naval Surface Warefare Centre, Carderock Division, US Navy and resulted in 157 runs at different sea conditions, speeds and headings. Full details of trials, the data acquisition system and instrumentation can be found in Brady et al. [18] and Bachman et al. [19]. High values of vertical accelerations up to $1.21 \mathrm{~g}$ at LCG and 5.41g at bow were reported, Applebee [20]. The available runs were Hat1_59 for head seas and Nor3_71 for oblique seas. Run Hat1_ 59 was selected for the proposed analysis in the head seas condition. It was noted that all the gauges had an inconsistent bias. This bias was removed so that a mean value of zero is set up for all gauges, which means that at still water condition before departure all signals from all gauges should point to zero. The same procedure was applied for the motion data. Bias was removed from all accelerations (at the bow and centre of gravity) and roll angle. The situation for pitch angle and relative bow motion was different. The ship sustained a static trim at departure of about $1 \mathrm{~m}$ by the bow, Brady [21]. At this condition, the trim angle was 0.70 degrees and therefore, the mean of the pitch angle during trials should have this value based on the assumption that the change in LCG due to fuel consumption and other consumables is minimal. The validity of this 
assumption arose from the close position of trial course to the departure point (about 50 miles), Bachman et al. [19]. The same procedure is applied to the relative bow motion record. The distance between the sensor location and the still water height is calculated based on the departure condition and the drawings supplied by INCAT for the sensor locations details. The calculations led to a static bow height of $6.45 \mathrm{~m}$, which should be the mean of the relative bow height signal. The wave height signal was de-biased so that it has a zero mean. All data units were converted to SI Units system where applicable. To validate the methodology, slamming is not considered and hence the data sample should be characterized by a 'smooth' response signal without any slamming or whipping effects. Similarly, the analysis is concerned with head seas and, strictly speaking, perfect head seas. Run-Hat1_59 was a head seas run at 20 knots in sea-state 5 as defined by NATO North Atlantic Sea State Chart Applebee [20] and Bachman et al. [19]. Head seas condition was regarded to be head seas if the direction of the predominant wave direction is within a limit of $\left[157.5^{\circ}, 202.5^{\circ}\right]$ relative to the ship. Therefore, some asymmetry between port and starboard responses is expected when the heading is not exactly $180^{\circ}$. Figure 2 , which plots equivalent gauges on the port and starboard sides of the vessel, illustrates the effect of non-perfect head seas in those points, which are away from the line of load symmetry.



Figure 2, Asymmetric Response at Fr 26, T1_5 (P) and T1_8 (SB)

The selection of a subset from the $20 \mathrm{~min}$. trials data for detailed analysis was carried out first using visual inspection to find the parts of the strain signal where there was no slamming or whipping. The selection was then refined through two steps. Firstly, a unit step function $s(t)$, Figure 3, was defined so that:

$$
s(t)= \begin{cases}1, & {\left[\varepsilon_{d}(t) \leq\left(\sigma_{\varepsilon d}\right)\right]} \\ 0, & {\left[\varepsilon_{d}(t) \geq\left(\sigma_{\varepsilon d}\right)\right]}\end{cases}
$$

The periods where $s(t)$ has a continuous value of 1 is regarded as close as to a symmetric condition as shown in Figure 3. A further investigation was carried out based on the roll angle record. It is believed that asymmetric sea headings would create asymmetric loading conditions on both of the demi-hulls. Consequently, transverse motion is expected in the form of higher rolling angles. The maximum roll angle in Run Hat1_59 was about $5^{\circ}$ which is significant for this type of vessel, Davis and Holloway [22]. Two samples were selected with both of them satisfying the smoothness condition. Sample "A"; $t=[905,917]$, has a high maximum roll angle of about $4^{\circ}$ while sample "B"; $\mathrm{t}=[928,935]$, has a low maximum roll angle of $1.5^{\circ}$, Figure 4. Sample "A" was selected to investigate the effect of loading asymmetry in head seas condition on the comparison between trials and finite element strains.

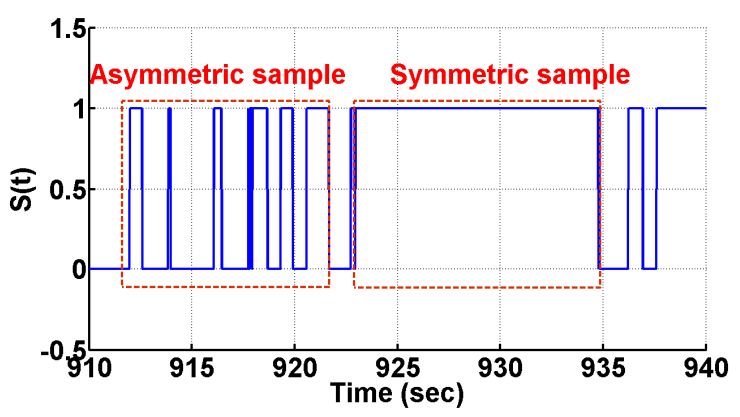

Figure 3, Unit Step Test Function

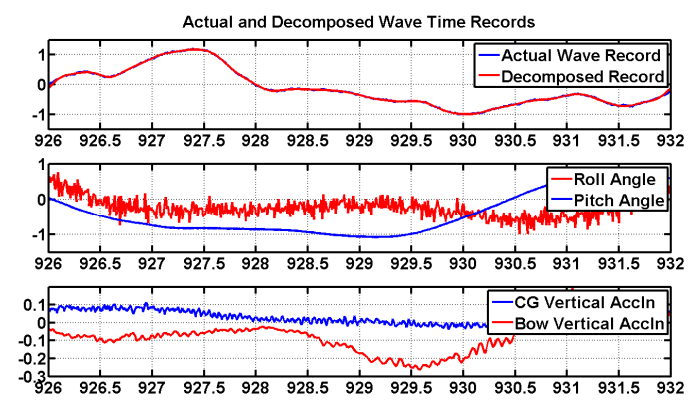

Figure 4, Trials data example for sample (B).

\section{FINITE ELEMENT MODEL}

The global finite element model was prepared by Revolution Design using the software package PATRAN/NASTRAN from MSC Software. The model was originally for Hull 057 which was used as a highspeed passenger/car ferry. The lines of both hulls are similar except that Hull 061 (HSV-2) is fuller below the chines. It was assumed that these minor changes in dimensions below the chines would not affect the overall global strength calculations. The global model is characterised by structural simplifications. For example, the centre girder flange was not modelled as well as most of the bracketed connections. Modelling of structural details in a global finite element model is impractical and irrelevant to the objective of global analysis. The original model was built using the laminate technique, mainly to reduce the model building time. In this technique, the stiffened panels were modelled as a composite structure of three layers. 
The layers represented the shell plating (isotropic properties), the stiffener's web and the stiffeners flange respectively (with zero stiffness in the transverse direction). Only the superstructure raft was modelled explicitly in the global FE model. The fully loaded superstructure mass was distributed using a combination of lumped mass elements and scaled material densities for the raft beams. The original model was built in an overall coarse mesh. Fine meshes were introduced in some areas where stress concentrations were expected. Further re-meshing was applied in way and around the strain gauge positions to obtain a clear representation of stress distributions and smooth strain contours. The global model, after remeshing and adjustments of weight and cargo distributions, had 91731 quad elements, 2284 triangular elements, 93123 nodes, 194 MPC elements, 77 beam sections, and 558738 DOFs.

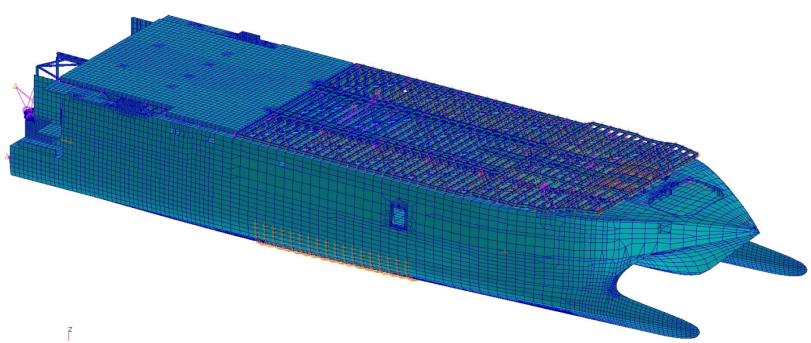

Figure 5, Hull 061 finite element model

Modelling of stiffened panels as laminate composite has not been previously assessed or compared to the previous finite element technique used by Revolution Design where plating was introduced as shell elements and stiffeners as beam elements. The only reason to change to the new technique was the short model building time. Due to the nature of the proposed procedure, where the finite element strain at a specific location is compared to trials values, it was first necessary to evaluate the accuracy of the laminate modelling technique in determining the exact stress distribution. A stiffened panel was modelled in three distinct configurations. Configuration (A) simulated the panel as laminates of the same material and properties as used by INCAT model. Configuration (B) simulated the plates as shell elements while the stiffeners are modelled as beam elements. Configuration (C) simulated the panel as constructed from plates, i.e., the stiffener's web and flange were also modelled as plates. The three configurations were loaded with a uniform pressure load with hinged edges. Comparing the results from the different models led to the following conclusions:

- The laminate modelling technique does not provide sufficient local resolution of strains required for correlation with strain gauges as is required in the present study.

- The modelling of plates and stiffeners as shell elements is too time consuming to use as a refining technique for each strain gauge location.

- The modelling of stiffeners as beam elements gives reasonable results provided that the strain gauges are not installed on the stiffeners that are modelled as beam elements.

\subsection{MESH REFINEMENT OF STRAIN GAUGES LOCATIONS}

Since, the INCAT model was originally built using the laminate technique, re-building the complete model using plate and beam stiffeners was impractical. Hence, configuration (B) modelling technique was introduced in way and around the location of the strain gauges only. That is to model the centre girder web and flange as shell elements (the flange was not modelled at all in the original model), the keel plate as shell element stiffened with one beam element and leaving the garboard strakes as originally modelled in laminates.

A smooth transition of mesh density from a coarse mesh to a fine one near the strain gauges should be guaranteed. In fulfilling this requirement, six frame spacings were included in the refinement process; i.e. three forward the gauge location and three abaft it. Transversely, five longitudinal spacings were included each side of the gauge location. The mesh density is a critical factor due to its direct effect on the run time and results accuracy. A test was made to investigate the required meshing density with respect to the existing coarse mesh. The original coarse mesh was constructed so that a single element is located between transverse frames. In this test, the mesh was reconstructed using three elements between transverse frames. The stress level was increased by about $40 \%$ more than the original mesh, Figure 6.

Essentially, the more nodes which exist in the model, the better a model's ability to converge to steady state results. For the case study under consideration, increasing the refinement level did not add much to the convergence to the maximum stress level. However, it was necessary to obtain smooth stress contours at the strain gauge location. The shape of individual elements also has a direct impact on the accuracy of local data and the resulting convergence. Therefore in addition to mesh size, element quality in areas of interest should be controlled (Adams, et al., 1999) [17]. In this work, it was decided to obtain a fine mesh around the strain gauge of $50 \times 50 \mathrm{~mm}$ quadrilateral elements as practical as possible and increase the mesh size away from the strain gauge location. 




Figure 6, Von Mises Stresses Increased by $40 \%$ for 3 Elements between Frames

\subsection{LOADING CONDITION AND CENTRE OF GRAVITY}

To equate the FE model to the trials condition all mass elements representing cars and trucks were removed, but additional mass elements were added to account for the 650 tonnes of fuel on board. Structural simplifications in the model, such as the lack of centre girder flange, bracketed connections, welding details and bolted connections caused a lower lightship displacement than required and an incorrect LCG value when compared to weight sheet calculations, Revolution Design [23]. Much effort was conducted to achieve an LCG as close as possible to the real trial's condition. However for the lightship condition an aft balance weight of 96 tonnes was divided between 4 nodes located approximately $1 \mathrm{~m}$ aft of the transom and connected to the model by MPCs. This is a standard technique used by Revolution Design to adjust the position of longitudinal centre of gravity and is accepted by DNV. This solution resulted in high stress hot spots close to the transom but they are distant from the strain gauge locations under consideration and their effect is believed to be local. The loading condition for the ship before trials was derived from the ship drafts which were recorded before departure to be $4 \mathrm{~m}$ forward and $3 \mathrm{~m}$ aft at the draft marks locations Brady [21]. Whilst some masses were known, such as the instrumentation trailer Brady et al. [18], other masses were estimated so that the required trials displacement was achieved. For Run Hat1-59, which was 50 miles distant from the departure point, the fuel load was assumed to be at full capacity, with the consumed fuel to the trial site being regarded as insignificant with respect to the ship's displacement.

\section{WAVE LOADS MODEL}

The proposed loading model is dedicated to vertical bending moment. Other wave loads during this simulation are neglected. Modelling of wave loads in a ship finite element model is a challenging task. The difficulty level depends on the handling of the considered wave loadings (static or dynamic) and the interaction with other codes to calculate these loads. Tailored finite element analysis packages for ship structural analysis, such as MAESTRO, has built-in functions to define the waterline (still or sine wave waterline) and apply pressure loads to the target elements Proteus Engineering [24]. The package GL.ShipLoad, developed by Germanischer Lloyds, can import a NASTRAN or ANSYS finite element model through a converter module and compute the balanced nodal load case based on strip theory, Cabos et al. [12]. Hydrodynamic/Structural analysis packages such as NAUTICUS, developed by DNV, can link the hydrodynamic loads to a built-in finite element analysis module D.N.V. [25]. The applied loads to the global finite element model depend on the purpose of analysis but in general they can be classified as follows:

- Hydrostatic force system.

- Inertia force system due to rigid body motions.

- Hydrodynamic forces represented in the form of the hydrodynamic coefficients; added mass, damping and restoration forces and wave excitation forces.

For example, for a longitudinal global strength analysis, the lateral forces due to fluid pressure can be neglected although they are approximately of the same order as the split forces. That is possible because they do not contribute to longitudinal strength calculations and are only a local effect as they act on both inboard and outboard sides of each demi-hull. Pitch connecting moments can also be neglected in symmetric head seas analysis. DNV Rules, D.N.V. [16],for direct calculation methods allow the possibility of modelling wave loads as "point line loads" or as pressure loads that were obtained from a hydrodynamic analysis. Then, for a longitudinal strength analysis, the vertical components of the static/dynamic pressure are those that contribute to the global longitudinal strength. In other words, they are the components acting on the vessel's bottom structure. The procedure used for load application is to calculate the force per frame and then distribute it evenly over three nodes per frame. Two nodes are at the chines and another node on the keel at the demi-hull centreline. The suggested analysis procedure is to select a momentary observation of strain record and then try to "balance" the ship on the corresponding actual wave profile. Balancing is achieved by making use of the trial's data; namely the time records of wave height, relative bow motion, bow vertical acceleration, LCG vertical acceleration and trim angle, instead of balancing the ship on an imaginary wave of a specified length, height and phase angle.

In the current study, which is an introduction to further studies on slamming response where the responses are compared to trials data, it is very important to replicate the actual loading conditions so that the comparison is meaningful.

The general equation of motion for coupled heave and pitch in the vertical direction can be written as:

$$
\begin{aligned}
& {\left[M+A_{33}(\omega, t)\right] \bar{\xi}_{3}(t)+B_{33}(\omega, t) \cdot \bar{\xi}_{3}(t)+} \\
& C_{33}(t) \cdot \bar{\xi}_{3}+A_{35}(\omega, t) \cdot \bar{\xi}_{5}(t)+ \\
& B_{35}(\omega, t) \cdot \overline{\dot{\xi}}_{5}(t)+C_{35}(t) \cdot \bar{\xi}_{5}(t)+ \\
& \bar{F}_{3}^{H}(t)+\bar{L}_{i}+M \cdot \bar{g}+\bar{F}_{3}^{D}(t)+\bar{F}_{3}^{K}(t)=0
\end{aligned}
$$


By neglecting all the hydrodynamic forces, the equation of motion in the vertical direction can be reduced to:

$$
M \bar{\xi}_{3}(t)+\bar{F}_{3}^{H}(t)+\bar{L}_{i}+M \cdot \bar{g}=0
$$

Equation (4) represents a 'quasi-dynamic'solution, which is more precise than 'quasi-static', as the inertia and motion-control forces are included in the analysis. The terms $A_{33} \ddot{\xi}_{3}$ and $B_{33} \dot{\xi}_{3}$ are the major parts of the radiation forces, Beck et al. [26], and hence the other terms containing $\mathrm{A}_{35}$ and $\mathrm{B}_{35}$ are ignored. Diffraction forces can be neglected as well by assuming that the incident wave was not distorted due to the slenderness of the ship's hulls. Froude-Krylov forces are the forces extracted by the undisturbed wave on a restrained ship. They were neglected in comparison to the hydrostatic forces. The ship was equipped by a retractable T-foildesigned by Maritime Dynamics, Inc.-for motion control. The lift coefficient is given by Matitime Dynamics Inc. [27]:

$$
\begin{aligned}
& C_{L}=0.044 \alpha+0.03 \delta \\
& L_{i}=\left(0.5 \times \rho \times A_{f} \times U^{2}\right) C_{L}
\end{aligned}
$$

The restoration terms are the forces exerted by the surrounding fluid to oppose the body tendency to move within the surrounding fluid. Therefore, for a momentary observation, the change in position is neglected and thus the restoration terms may be omitted from the equation. The equation of motion in this case can be reduced to:

$$
\begin{aligned}
& {\left[M+A_{33}(\omega, t)\right] \bar{\xi}_{3}(t)+B_{33}(\omega, t) \cdot \bar{\xi}_{3}(t)} \\
& +\bar{F}_{3}^{H}(t)+\bar{L}_{i}+M \cdot \bar{g}=0
\end{aligned}
$$

$A_{33}$ and $B_{33}$ can be calculated as follows:

$$
A_{33}=\int_{0}^{L} a_{33} d x
$$

and

$$
B_{33}=\int_{0}^{L} b_{33} d x
$$

The coefficients $a_{33}$ and $b_{33}$ depend on the shape of the submerged hull form. The hull cross sections can be approximated to semi circular cylinders whose diameter is the waterline beam at each section. The added mass and damping of a semi-cylindrical cross section is well known and verified in the literature, Ursell [28] Newman [29], Bishop and W.G.Price [30], Holloway [31] and Faltinsen [32]. The interaction between the two demi-hulls was neglected.

Figure 7 and Figure 8, Holloway [31], were used to determine the coefficient at a frequency equal to the apparent structural response frequency during the sample under consideration.

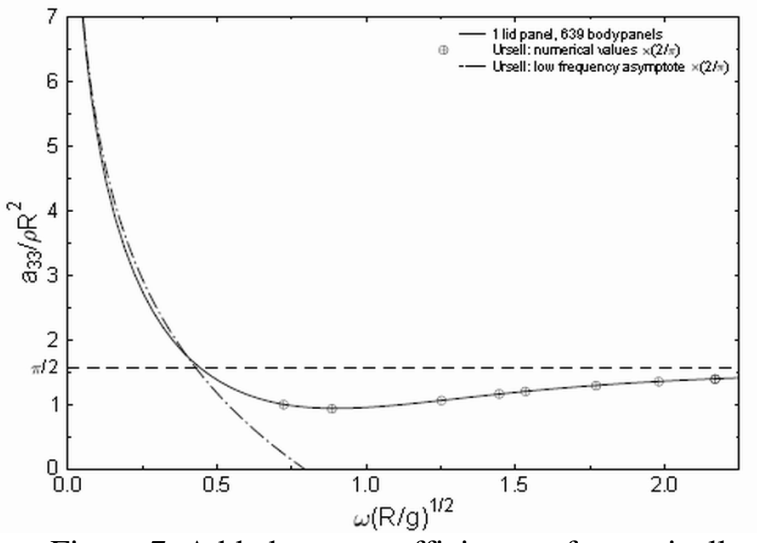

Figure 7, Added mass coefficient $\mathrm{a}_{33}$ for vertically oscillating cylinder, Holloway [31].

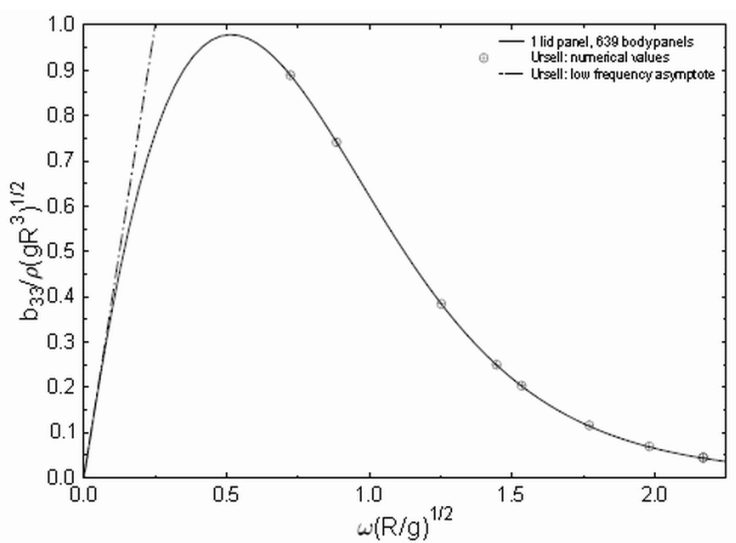

Figure 8, Damping coefficient $b_{33}$ for a vertically oscillating cylinder, Holloway [31].

\subsection{DETERMINATION OF WATER PROFILE AND WATERLINE}

A study by Thomas [17] has shown that a dominant sine wave component may be identified through the wave height record and taken into consideration in a similar study, but it becomes very difficult if the wave record is fully random and a single sine wave can not be identified. A wave height record was obtained during the trials by means of a single point sensor (TSK wave height system) located $366 \mathrm{~mm}$ aft of frame 75 . This means that the wave height is measured only at the bow. By assuming that the wave record will maintain its value as the ship move through, a Fourier Transform (FT) can be used to decompose a window of wave height record, which corresponds to the moment under consideration. The advantage of using a FT is the transformation of wave height time-record at a certain moment to a wave profile along the ship. A window of a time record of length $\mathrm{T}_{\mathrm{H}}$ seconds can be represented by a Fourier series as follows, Lloyd [33]:

$$
\zeta(\mathrm{t})=\bar{\zeta}+\sum_{n=1}^{\infty}\left(A_{n} \cos \left(\omega_{n} t\right)+B_{n} \cos \left(\omega_{n} t\right)\right)
$$

Where: 


$$
\left\{\begin{array}{l}
\omega_{n}=\frac{2 \pi n}{T_{H}},(n=1,2,3, \ldots \ldots \infty) \\
A_{n}=\frac{2 \pi}{T_{H}} \int_{0}^{T_{H}} \zeta(t) \cos \left(\omega_{n} t\right) d t \\
B_{n}=\frac{2 \pi}{T_{H}} \int_{0}^{T_{H}} \zeta(t) \sin \left(\omega_{n} t\right) d t
\end{array}\right\}
$$

The required number of terms to obtain a satisfactory match was described as either infinite Hughes [34] and Lloyd [33], or large Bishop and W.G.Price [30] and Faltinsen [32]. However, for the current application it was found that 20 components were sufficient to obtain a reasonable agreement between actual and synthesised wave height signals. Given the relation between wave frequency and frequency of encounter as:

$$
\omega_{e}=\omega+\frac{U}{g} \omega^{2}
$$

Then,

$$
\omega=\frac{g}{2 U}\left[\sqrt{1+\frac{4 \omega_{e} U}{g}}-1\right]
$$

The wave speed $\mathrm{C}$ can be expressed as

$$
C=\sqrt{\frac{g}{\omega}}
$$

The relative speed by which the individual wave component is passing the ship is

$$
V_{r}=U+C
$$

Hence, the decomposed component, $i$, can be expressed as a function of the longitudinal position, $x$; measured from the transom along the ship as:

$$
\left\{\begin{array}{l}
\xi_{c i}(x)=A_{n i} \cos \left[\omega_{e i} \cdot\left(\frac{T-(89.634-x)}{V_{r i}}\right)\right] \\
\xi_{s i}(x)=B_{n i} \sin \left[\omega_{e i} \cdot\left(\frac{T-(89.634-x)}{V_{r i}}\right)\right]
\end{array}\right\}
$$

Equation (16) decomposes the wave height signal into a series of sinusoids that are expanded over the hull length. The superposition of these components provides the waterline profile. Depending on the relative bow motion signal, which gives the distance between the TSK sensor and the water surface, the decomposed waterline can be shifted to the correct position.

The relative bow motion was not initially biased with an average of zero. However, the relative bow motion should be averaged around its initial reading at the departure condition. This average was calculated based on the TSK sensor location and the still waterline draftmarks at departure condition, Brady [21]. The same procedure was conducted for the pitch angle record.

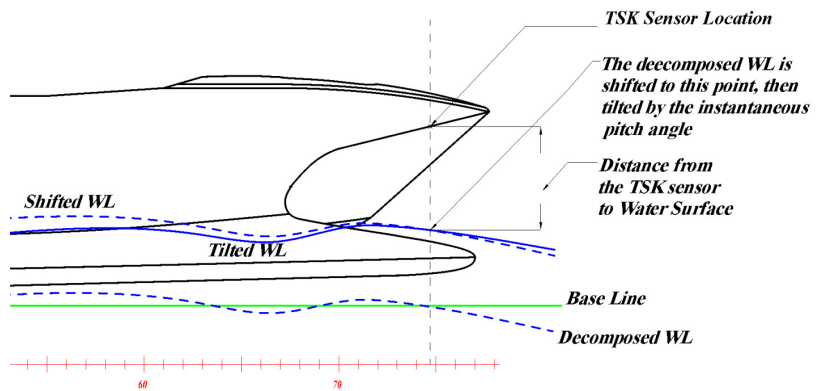

Figure 9, Determination of waterline.

The waterline was then tilted around the forward point under the TSK sensor by the amount of the instantaneous pitch angle at the instant under consideration. Figure 9 shows the bow profile with the location of the TSK marked. The decomposed water surface was located first at the base line indicating that the ship is out of water. Then, the ship is immersed in the water (or the waterline is shifted upward) to the correct relative bow motion record. Hence, the ship is trimmed (or the waterline is tilted) to the corresponding trim angle around the point exactly under the TSK position. Calculation of the buoyancy forces was then performed using the ship's Bonjean curves. Inertial loads (linear and angular) generated by rigid body accelerations can be included in the finite element load model. The solution was run first without hydrodynamic terms; added mass and damping. Then, the solution was repeated taking into account the added mass and damping to explore their effect on the results.

\section{RESULTS AND DISCUSSION}

The analysis of the current two sea trials samples led to the development of 37 load cases at intervals of $0.5 \mathrm{sec}$. The finite element strain time histories were plotted for each gauge, as well as the corresponding trials values. According to the proposed analysis procedures, the finite element strains are due to the total loading (still water load + wave loads). It was expected to find a difference in the form of shifted points but following the same behaviour of the trials data points, as demonstrated in Figure 10. This shift resulted from the fact that the strain gauges are measuring the difference between the total seaway load signal and the strain condition when they were installed. Ideally, this condition can be assumed as the still water condition. Therefore, the finite element results should be deducted by this amount before establishing any comparison. However, the magnitude of the still water strains is debatable due to the following assumptions:

- The strain gauges were installed while the ship was in the still water condition as specified in Brady [21].

- The ship was built exactly according to construction drawings.

- The residual stresses due to metal fabrication and welding were not accounted for.

- The trials loading condition was assumed to be correct. 
- $\quad$ Adjustments of the balance of the strain gauge bridges were unknown.



Figure 10, FE results shift due to still water strains.

Figure 11 shows the applied shift for each sample in comparison to still water strains. The shift was based on keeping the same average for both trial's strains and those from FEA so that the correlation between FE and trial's results is performed correctly. Once the FE results were shifted, each strain gauge data can be plotted on a scattergram on which a linear relationship is expected at a slope of 1, an example is shown in Fig 12.



Figure 11, Applied strains shift in comparison to still water strains for samples A \& B.

A measure of this linearity is the correlation coefficient which is defined as:

$$
c c\left(\varepsilon_{T}, \varepsilon_{F}\right)=\frac{\sum_{i=1}^{n}\left[\left(\varepsilon_{F_{i}}-\bar{\varepsilon}_{F}\right) \cdot\left(\varepsilon_{T_{i}}-\bar{\varepsilon}_{T}\right)\right]}{n \cdot \sigma_{F} \cdot \sigma_{T}}
$$

The correlation coefficient must have a value that lies in the range $[-1,1]$. The sign of the correlation coefficient reveals the direction of the relationship between the two variables. A positive value indicates that both variables are directly proportional while a negative value represents a reverse proportional relationship. A zero correlation coefficient insures that a linear relationship is poor but it does not eliminate the possibility of other nonlinear relationships, Tashman and Lamborn [35]. However, the present application deals with pure linear relations and hence other types of relations are not applicable. Figure 12 shows an example for a scattergram for the gauge T1_5 where the correlation coefficient is $86.61 \%$. Table 1 summarizes the correlation coefficient for the keel gauges and their averages between port and starboard values.

\begin{tabular}{|c|c|c|c|c|c|}
\hline \multirow[t]{2}{*}{ Gauge } & \multirow[t]{2}{*}{ Location } & \multicolumn{2}{|c|}{ Sample A } & \multicolumn{2}{|c|}{ Sample B } \\
\hline & & & Ave & & Ave \\
\hline T1_5 & Aft, $\mathrm{P}$ & 46 & \multirow{2}{*}{34} & 86.6 & \multirow{2}{*}{79.8} \\
\hline T1_8 & Aft SB & 22 & & 73 & \\
\hline T1_6 & Midship, P & 45 & \multirow{2}{*}{22} & 79 & \multirow{2}{*}{67} \\
\hline T1_9 & Midship, SB & 8 & & 55 & \\
\hline T1_7 & $\mathrm{F}^{\prime} \mathrm{d}, \mathrm{P}$ & 10 & \multirow{2}{*}{3} & 33 & \multirow{2}{*}{5} \\
\hline T1_10 & F'd SB & -4 & & -23 & \\
\hline
\end{tabular}

Table 1, Correlation coefficients for keel gauges.

The correlation coefficient was found to be a maximum of $86.6 \%$ towards the stern but reduces to $80 \%$ at amidships and has its lowest value for the bow gauges of $33 \%$. This is due to the asymmetric loading effects being more severe towards the bow when the incident waves impact the wave-piercing section of the demihulls. These values are further reduced for sample (A) to be $46 \%$ at the stern gauges and $10 \%$ at the bow.

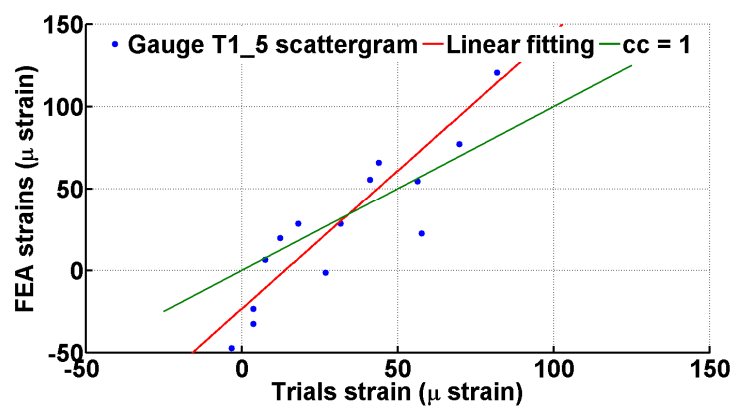

Figure 12, Sample B, gauge T1_5 correlation between trials and FEA.

Averaging port and starboard strains removes some error but it does not eliminate it. It is more convenient to consider the RMS strains from a design perspective rather than the time history of individual strain gauges. Thus a scattergram is plotted for the RMS values of all the keel gauges.

In Figure 13, the FE strains RMS for each gauge are plotted against the corresponding trials strain RMS. The overall correlation coefficient was found to approach a value of $95.5 \%$. The asymmetric loading conditions inherent to sample B reduced the correlation coefficient for all gauges to a value of $80.2 \%$. 




Figure 13, Sample B FE element strains RMS versus trials strains RMS for all gauges.

\subsection{EFFECT OF HYDRODYNAMIC FORCES}

The hydrodynamic forces according to traditional strip theory are calculated as discussed in section 5. It was found that the added mass and damping coefficients have a negligible effect on calculations at this range of wave loadings. Figure 14 shows how small are the added mass and damping, when compared to hydrostatic forces under the actual wave profile when slamming is not considered.
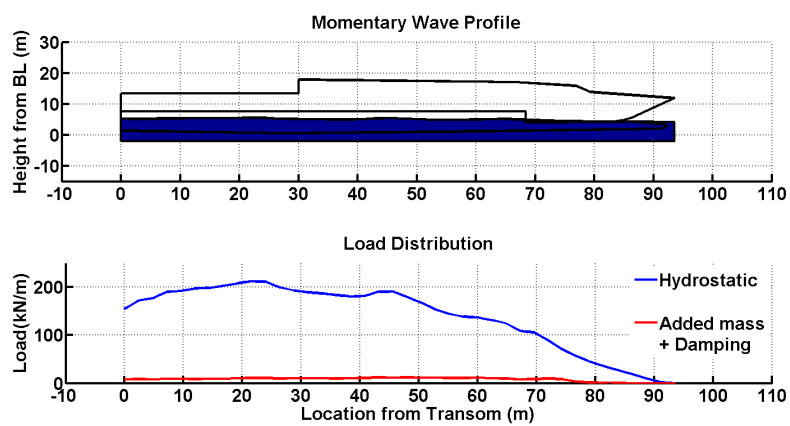

Figure 14, Sample (B), t=929, Added Mass and Damping Contribution to Wave Loads

\section{CONCLUSIONS}

Using FEA in reverse engineering of the structural ship design problem for high speed wave piercing catamarans seems to be promising and provides a reasonable accuracy when uncertainties in load application and structural modelling are considered. The current study shows that comparing the time histories of trial's strains with those from FEA is very hard and sometimes gives low correlation due to the asymmetric loading conditions within the defined limits of head seas heading. On the other hand, the whole FE strain time history, expressed in terms of strain RMS, has a much better agreement with the corresponding trial's strains RMS. In other words, direct comparison with respect to time is nearly impossible in a 'quasidynamic' solution. However, the methodology presents a reliable design wave load for a given sea state conditions. It was also found that the hydrodynamic components, represented in added mass and damping in heave, have a minor effect on results when slamming is not considered. The study clearly shows that the direction of wave train has a direct impact on the results and proper means should be employed to define a correct load model for oblique seas. The next stage of the current work is to test these modelling techniques when slamming is considered.

\section{ACKNOWLEDGMENT}

The authors would like to thank Mr Gary Davidson and Mr Tim Roberts of Revolution Design for their valuable input into this work. In particular $\mathrm{Mr}$ Davidson's advice concerning finite element modelling is acknowledged.

\section{REFERENCES}

[1] N. Tanaka, S. Sanbongi, and T. Kawaii, "A Torsional Strength Analysis on the Container Ship by means of the Finite Element Procedure and Full-Scale Testing," International Shipbuilding Progress, pp. 198214, 1971.

M. J. Kaldjian, J. R. Woodward, and W. R. Reid, "Deflection of Greate Lakes Ore Carrier Hull Structure by Finite Element Analysis," presented at SNAME, Great Lakes and Great Rivers Section, Michigan, USA, 1982.

N. G. Pegg, T. A. Vernon, L. Wegner, and W. C. E. Nethercote, "Finite Element Prediction of Measured Bow Flare Plate Stresses under Dynamic Wave Loading," Trans RINA, pp. 135-143, 1988.

B. Hay and J. Bourne, "Characteristics of Hydrodynamic Loads Data for a Naval Combatant," presented at International Conference on Hydroelasticity in Marine Technology, 1994.

[5] J. Sikora, H. Paul, and S. Brian, "DTRC report," DTRC SSPD-91-173-43, 1991.

[6] J. P. Sikora, H. M. Ford, and J. L. Rodd, "Seaway Induced Loads and Sructural Response of the HSV-2," Naval Surface Warfare Center, Cardrock Division NSWCCD-65-TR-2004/11, 2004.

[7] D. C. Stredulinsky, N. G. Pegg, and Gilroy, "Motion, Load and Structural Response Predictions and Measurements on CFAV Quest," Trans. RINA, vol. Part B, No. 141, pp. 117-123, 1999.

[8] M. Yamamoto, H. Sugimoto, K. Kada, and K. Higashi, "Global Strength Analysis of Wave Piercing Catamarans," presented at FAST '93, Yokohama, Japan, 1993. 
Naval Surface Warfare Center, Cardrock Division 5500/0421, 2004.

[10] R. J. Tulk, "The BC Ferries' Catamarans," IMarE, vol. 111, Part 3, pp. 145-154, 1999.

[11] B. P. Phelps, "Determination of Wave Loads for Ship Structural Analysis," DSTO Aeronautical and Maritime Research Laboratory, Melbourne DSTO-RR-0116, 1997.

[12] C. Cabos, H. Eisen, and M. Krömer, "GL.ShipLoad: An Integrated Load Generation Tool for FE Analysis," presented at COMPIT, Delft, 2006.

[13] O. A. Hermundstad, "Theoretical and Experimental Hydroelastic Analysis of High Speed Vessels",PhD Thesis, in Department of Marine Structures, The Norwegian Institute of Technology, 1996.

[14] A. Rosen, "Loads and Responses for Planing Craft in Waves",PhD Thesis, in Aeronautical and Vehicle Engineering, 2001.

[15] G. Wang, S. Tang, and Y. Shin, "A Direct Calculation Approach for designing a Shipshaped FPSO's Bow Against Wave Slamming Load," presented at Twelfth International Offshore and Polar Engineering, Kitakyushu, Japan, 2002.

[16] D.N.V., Rules for High Speed, Light Craft and Naval Surface Craft, July 2005: DNV, 2005.

[17] G. Thomas, "Wave Slam Response of Large High Speed Catamarans",PhD Thesis, in Department of Mechanical and Civil Engineering, University of Tasmania, 2003.

[18] T. F. Brady, B. R.J., M. J. Donnelly, and D. B. Griggs, "HSV-2 Swift Instrumentation and Technical Trials Plan," Naval Surface Warfare Center, Cardrock Division NSWCCD-65-TR2004/18, 2004.

[19] R. J. Bachman, D. A. Woolaver, and M. D. Powell, "HSV-2 Swift Seakeeping Trials," Naval Surface Warfare Center, Cardrock Division, USNavy NSWCCD-50-TR2004/052, 2004.

[20] T. Applebee, "Data Summary of Higest Five Vertical Bow Accelerations for HSV-2Swift Octagons during Feburary and May 2004,"

[21] T. F. Brady, "Swift (HSV-2) Blue Games Structural Response Summary, Quicklook Report," Naval Surface Warfare Cwnter, Cardrock Division 2004.

[22] M. Davis and D. Holloway, "Effect of Sea, Ride Controls, Hull Form and Spacing on Motion and Sickness Incidence for High Speed Catamarans," presented at FAST'03, Naples, Italy, 2003.

[23] Revolution Design, "MSC 061 Summary Weight Estimate," MSC 061-99-30-005, 2003.

[24] Proteus Engineering, MAESTRO; Basic Ship Design (2007)

$<$ http://www.proteusengineering.com/maestro. htm\#Ship-Based\%20Loading $>$ at 10th of July 2007.

[25] D.N.V., FEA Tank and 1A1 (2007) $<$ http://www.dnv.com/software/nauticus/nauti cusHull/feaTank.asp $>$ at 9th of July 2007.

[26] R. F. Beck, W. E. Cummins, J. F. Dalzell, P. Mandel, and W. C. Webster, Motion of Waves and Controllability, vol. III, 2 ed. New Jersy: SNAME, 1988.

[27] Matitime Dynamics Inc., "Foundation Design Loads for $8.63 \mathrm{~m}^{2}$ Retractable T-Foil for INCAT Tasmania, Hull 061," MD-R-2522$01,2003$.

[28] F. Ursell, "On the heaving Motion of a Circular Cylinder in the Surface of a Fluid," Quarterly Journal of Mechanics and Applied Mathematics, vol. 2, pp. 218-231, 1949.

[30] E. R. D. Bishop and W.G.Price, Hydroelasticity of Ships. London: Cambridge University Press, 1979.

[31] D. Holloway, "A high Froude Number Time Domain Strip Theory Applied to the Seakeeping of Semi-SWATHs",PhD Thesis, in University of Tasmania, 1998.

[32] O. M. Faltinsen, Hydrodynamics of HighSpeed Marine Vehicles. New York: Cambridge University Press, 2005. 
[33] A. R. J. M. Lloyd, Seakeeping Ship Behavioour in Rough Weather. Southampton: Ellis Horwood, 1989.

[34] O. F. Hughes, Ship Structural Design. A Rationally-Based, Computer-Aided Optimisation Approach: SNAME, 1988.

[35] L. J. Tashman and K. R. Lamborn, The Ways and Means of Statistics. new York: Harcourt Brace Jovanovich, 1979.

\section{AUTHORS BIOGRAPHY}

Walid Amin holds a BSc (1995) and MSc (2000) in Naval Architecture and Marine Engineering at Alexandria University, Egypt. Mr Amin works as an Assistant Lecturer at the same department and currently a $\mathrm{PhD}$ candidate at University of Tasmania. He has also worked in consultancy as a naval architect and design engineer in the field of offshore structures and super yacht design and construction.

Prof. Michael R. Davis is Professor of Engineering at the University of Tasmania. He is currently working in the area of ship dynamics and propulsion, with particular reference to high speed ship motion and wave loads, and has published and acted as consultant in heat transfer, fluid dynamics, vibration and noise. Professor Davis is a Fellow of the Institution of Engineers, Australia and a Fellow of the Royal Aeronautical Society.

Dr Giles Thomas is a Senior Lecturer at the Australian Maritime College, an institute of the University of Tasmania. He received his $\mathrm{PhD}$ in 2003 from the University of Tasmania for his work on the slamming of large high-speed catamarans. He is currently a Chief Investigator on a collaborative project with Incat and Revolution Design investigating asymmetric and nonlinear loads on high-speed catamarans. 